\title{
Happoseosten ja kantaja-aineen vaikutukset vieroitetuilla porsailla
}

\author{
Kirsi Partanen ${ }^{1)}$, Anu Artjoki ${ }^{1)}$, Sini Perttilä ${ }^{1)}$, Hilkka Siljander-Rasi ${ }^{1)}$, Sinikka Pelkonen ${ }^{2)}$, Tarja \\ Pohjanvirta $^{2)}$ ja Erkki Virtanen ${ }^{3)}$ \\ ${ }^{1)}$ MTT Sikatalous, Tervamäentie 179, 05840 Hyvinkää, kirsi.partanen@mtt.fi, hilkka.siljander- \\ rasi@mtt.fi, sini.perttila@mtt.fi \\ ${ }^{2)}$ EELA, Kuopion tutkimusyksikkö, sinikka.pelkonen@eela.fi, tarja.pohjanvirta@eela.fi \\ ${ }^{3)}$ Kemira GrowHow Oyj, PL 900, 00181 Helsinki, erkki.virtanen@kemira-growhow.com
}

\section{Tiivistelmä}

Porsasrehuihin lisätään orgaanisia happoja tai happoseoksia parantamaan porsaiden kasvua ja rehuhyötysuhdetta sekä vähentämään ripulin esiintymistä vieroituksen jälkeen. Useat nestemäiset hapot ovat kuitenkin pistävän hajuisia ja syövyttäviä, mikä hankaloittaa niiden käsittelyä rehunvalmistuksessa. Nestemäisten happojen imeyttäminen kiinteään kantaja-aineeseen helpottaisi happojen käsittelyä, mutta kantaja-aineen vaikutusta happojen tehoon ei tunneta. Tässä tutkimuksessa selvitettiin, miten happoseosten lisääminen porsasrehuun joko nestemäisenä tai piimaakantajaaineeseen imeytettynä vaikuttaa vieroitettujen porsaiden kasvuun, rehuhyötysuhteeseen, ripulisuuteen ja sonnan E. coli -bakteerien määrään. Tutkittavat kaksi happoseosta olivat muurahaishapponatriumformiaatti-fosforihappopohjaisia ja niissä oli sama määrä joko kaliumsorbaattia tai maitohappoa. Molempia happoseoksia lisättiin rehuihin $4,9 \mathrm{~g} / \mathrm{kg}$ joko nestemäisenä tai piimaahan imeytettynä. Piimaata oli sekä hapottomassa että happoseoksia sisältäneissä rehuissa 0 tai $5,1 \mathrm{~g} / \mathrm{kg}$. Sorbaattia ja maitohappoa sisältäneet happoseokset laskivat porsasrehun $\mathrm{pH}: \mathrm{n} 5,5:$ stä 5,2 ja 5,1:een.

Kokeessa oli 384 vieroitettua porsasta 48 pahnueesta. Porsaat vieroitettiin 25-36 päivän ikäisinä. Porsaat kasvatettiin neljän porsaan karsinoissa ja jokaisessa koekäsittelyssä oli 16 karsinaa. Porsaat olivat kokeessa 25 päivän ajan ja ne saivat rakeistettua rehua automaatista vapaasti. Ripulihavainnot (ulosteen kiinteys) merkittiin ylös päivittäin. Porsailta kerättiin sotanäytteitä (12 karsinasta per käsittely) 5,10 ja 20 päivän kuluttua vieroituksesta ja näytteistä määritettiin vesipitoisuus sekä $E$. coli -bakteerien kokonaismäärä ja hemolyyttisten $E$. coli -pesäkkeiden osuus.

Porsaiden vieroituspaino oli piimaata sisältäneillä ruokinnoilla pienempi $(10,0$ vs. $10,3 \mathrm{~kg}, \mathrm{P}<$ $0,05)$ kuin kantaja-aineettomilla ruokinnoilla, mikä johtui hieman nuoremmasta vieroitusiästä $(30,5$ vs. 31,4 pv). Kantaja-aineettomien ja piimaata sisältäneiden ruokintojen välinen porsaiden painoero kasvoi kokeen edetessä 1,3 kg:n suuruiseksi, sillä kantaja-aineen käyttö hidasti porsaiden kasvua (306 vs. $342 \mathrm{~g} / \mathrm{pv}, \mathrm{P}<0,05)$. Piimaan kasvua hidastava vaikutus oli lähes merkitsevä $(\mathrm{P}=0,06)$ silloinkin, kun vieroituspainoa käytettiin kasvujen analysoinnissa kovariaattina. Piimaan käyttö huononsi myös rehuhyötysuhdetta (1,86 vs. $1,72 \mathrm{~kg} \mathrm{ka} / \mathrm{kasvu} \mathrm{kg}, \mathrm{P}<0,05)$. Porsaat kasvoivat hapottomilla sekä S- ja M-happoseoksia sisältäneillä ruokinnoilla keskimäärin 307,334 ja $330 \mathrm{~g} / \mathrm{pv}$ ja käyttivät rehua 1,86, 1,78 ja 1,74 kg kuiva-ainetta kasvukiloa kohti. Kumpikaan happoseoksista ei kuitenkaan vaikuttanut merkitsevästi porsaiden kasvuun eikä rehuhyötysuhteeseen. Happoseokset eivät vaikuttaneet ripulipäivien lukumäärään, eikä ripulin vakavuutta kuvaavaan ripuli-indeksin suuruuteen. Piimaakantaja-aine pienensi ripuli-indeksiä ensimmäisten 11 päivän aikana vieroituksen jälkeen kantaja-aineettomaan ruokintaan verrattuna (3,7 vs. 5,1, P <0,05), mutta ei enää myöhemmin.

Sontanäytteet kerättiin 5, 10 ja 20 pv vieroituksen jälkeen, jolloin 57, 65 ja $54 \%$ :ssa näytekarsinoista havaittiin ulosteen löystymistä tai ripulia. Sonnan vesipitoisuus pieneni suoraviivaisesti ajan myötä vieroituksen jälkeen, mutta $E$. coli -bakteerien määrä ja hemolyyttisten $E$. coli -pesäkkeiden osuus olivat suurimmillaan $10 \mathrm{pv}$ vieroituksesta ja pienimmillään $20 \mathrm{pv}$ vieroituksesta. Happoseoksilla ja kantaja-aineella ei ollut merkitsevää vaikutusta sonnan vesipitoisuuteen, E. coli-bakteerien kokonaismäärään eikä hemolyyttisten $E$. coli -pesäkkeiden osuuteen.

Tulosten perusteella 5,1 g piimaakantaja-ainetta $\mathrm{kg}$ :ssa porsasrehua huononsi porsaiden kasvua ja rehuhyötysuhdetta, vaikka se pienensikin ripulin vakavuutta kuvaavaa ripuli-indeksiä ensimmäisten 11 päivän aikana vieroituksen jälkeen. Useista hapoista ja suoloista koostetut happoseokset eivät 4,9 $\mathrm{g} / \mathrm{kg}$ lisäystasolla vaikuttaneet merkitsevästi porsaiden kasvuun, rehuhyötysuhteeseen eikä ripulisuuteen, eivätkä kantaja-aine ja happoseokset vaikuttaneet sonnan E. coli-bakteerien määrään.

Avainsanat: porsas, orgaaniset hapot, piimaa, kasvu, rehuhyötysuhde, vieroitusripuli, Escherichia coli 


\section{Johdanto}

Porsasrehuihin lisätään varsin yleisesti orgaanisia happoja, kuten muurahais-, maito- tai propionihappoa, minkä tarkoituksena on parantaa porsaiden kasvua ja rehuhyötysuhdetta sekä vähentää ripulin esiintymistä (Partanen ja Mroz 1999). Samaan tarkoitukseen käytetään myös orgaanisten happojen natrium-, kalium- ja kalsiumsuoloja, epäorgaanista fosforihappoa sekä yhä enemmän myös erilaisia happojen ja/tai suolojen seoksia. Happoseokset ovat mielenkiintoisia, koska seoksessa pienikin määrä jotain happoa tai hapon suolaa voi tehostaa hapon antimikrobisia ominaisuuksia ja lisätä sen tehoa kasvunedistäjänä. Esimerkiksi muurahaishapon kasvua edistävää vaikutusta on saatu parannettua sekoittamalla siihen pieni määrä (5\%) kaliumsorbaattia (Partanen ym. 2002).

Useimpien nestemäisten happojen käyttöä rehulisäaineena hankaloittaa niiden syövyttävyys ja voimakas, pistävä haju. Nestemäisten happojen käsiteltävyyttä voidaan kuitenkin parantaa imeyttämällä ne kantaja-aineeseen, kuten piimaahan. Piimaa koostuu fossiiliksi muuttuneista yksisoluisista piilevistä ja se on lähes puhdasta, kiteytymätöntä piioksidia (Korunic 1998), Piimaa on huokoista ja se voi imeä puolet painonsa verran nestettä tilavuuden laajenematta. Piimaata pidetään yleisesti turvallisena lisäaineena ja sitä käytetäänkin maataloudessa moniin tarkoituksiin, kuten hyönteisten torjuntaan viljassa ja jauhoissa sekä parantamaan rehujen juoksettuvuutta ja rakeiden laatua. Piimaan vaikutusta orgaanisten happojen tehoon kasvunedistäjänä on kuitenkin tutkittu vähän. Lihasioilla tehdyn kasvatuskokeen perusteella piimaahan imeytetty muurahaishappo-sorbaatti seos oli tehokas kasvun edistäjä jo varsin pieninä pitoisuuksina (1,5-6 g happoseosta/kg rehua, Partanen ym. julkaisematon). Piimaan kaltaisia, imeytymiskykyisiä maa-aineksia (zeoliitteja), kuten valkosavea käytetään mm. ehkäisemään ripulia sairastavien porsaiden kuivumista (Veldman ja Aar 1997). Siljander-Rasin ym. (2002) tutkimuksessa kaoliinivalmisteen käyttö pienensi sonnan vesipitoisuutta ja vähensi myös $E$. coli -bakteerien määrää porsaiden sonnassa.

Tämän tutkimuksen tavoitteena oli selvittää, miten kantaja-aineena käytetty piimaa vaikuttaa kahden happoseoksen tehoon porsaiden kasvunedistäjänä. Happoseokset olivat muurahaishapponatriumformiaatti-fosforihappopohjaisia ja niihin oli lisätty pieni määrä kalsiumsorbaattia tai maitohappoa. Tutkimuksessa selvitettiin myös kantaja-aineen ja happoseosten vaikutusta porsaiden ripulisuuteen ja miten sonnan vesipitoisuus ja $E$. coli -bakteerien määrä muuttuvat vieroituksen jälkeen.

\section{Aineisto ja menetelmät}

Koe-eläiminä oli 348 porsasta 48 pahnueesta, jotka vieroitettiin 25-36 päivän iässä. Jokaisesta pahnueesta otettiin kokeeseen kahdeksan mahdollisimman tasakokoista porsasta, jotka arvottiin kahteen neljän porsaan ryhmään. Nämä neljän porsaan ryhmät kasvatettiin $2,65 \mathrm{~m}^{2}: \mathrm{n}$ karsinoissa, joiden lattia-alasta $52 \%$ oli kiinteää betonilattiaa ja 48\% korotettua, muovista rakolattiaa. Kuivikkeena käytettiin kutterinlastua. Karsinoissa oli kaksi vesinippaa ja yksi rehuautomaatti (Groba Diplomat AS, Skælskør, Tanska). Kasvatusosaston lämpötila oli kokeen alkaessa $26^{\circ} \mathrm{C}$, ja sitä laskettiin viikoittain kahdella asteella kunnes saavutettiin $22^{\circ} \mathrm{C}$ :een lämpötila.

Koe tehtiin $2 \times 3$ faktorikokeena, jossa tutkittavina tekijöinä olivat piimaakantaja-aineen (kantaja-aineettomat ja piimaata sisältävät rehut) ja happoseosten käyttö porsasrehuissa (hapottomat ja kahta erilaista happoseosta sisältäneet rehut). Yhteensä koekäsittelyjä oli kuusi. Neljän porsaan karsinat arvottiin pahnueittain koekäsittelyihin epätäydellisten lohkojen koemallin mukaan (Cochran \& Cox 1957). Jokaiseen käsittelyyn tuli 16 karsinaa.

Tutkittavat kaksi happoseosta valmistettiin sekä nestemäisinä että kiinteinä. Nestemäiset happoseokset sisälsivät 15,3\% muurahaishappoa, 9,2 \% natriumformiaattia, 10,9\% fosforihappoa, 0,9 \% sitruunahappoa, 3,4 \% kaliumsorbaattia (S-happoseos) tai maitohappoa (M-happoseos) ja 51,3\% vettä. Kiinteät happoseokset olivat koostumukseltaan muutoin samanlaisia, paitsi veden asemesta niistä oli kantaja-aineena 51,3 \% piimaata (Damolin). Sekä nestemäisiä että kiinteitä happovalmisteita lisättiin rehuun $10 \mathrm{~g} / \mathrm{kg}$, ja niistä tuli rehuun $5,1 \mathrm{~g}$ piimaata ja/tai $4,9 \mathrm{~g}$ happoseosta $/ \mathrm{kg}$. Toiseen hapottomista rehuista lisättiin pelkkää piimaata $5,1 \mathrm{~g} / \mathrm{kg}$.

Koerehut optimoitiin siten, että ne täyttivät porsaiden ruokintasuositukset aminohappojen, kivennäisten ja vitamiinien osalta (MTT 2004). Lisäaineeton perusrehu sisälsi vehnää (50,5 \%), ohraa (25\%), kauraa (7\%), soijaproteiinia (8\%), heravalkuaisjauhetta $(5 \%)$, kasviöljyä $(1,06 \%)$, monokalsiumfosfaattia $(0,76 \%)$, ruokintakalkkia $(1,18 \%)$, kivennäis- ja vitamiiniseosta $(1,3 \%)$ sekä 
puhdasta lysiiniä $(0,18 \%)$ ja metioniinia $(0,01 \%)$. Kantaja-ainetta ja/tai happoseoksia sisältäneet rehuseokset pidettiin isoenergisinä muuttamalla vehnän (50,5:stä 48,8 \%:iin) ja kasviöljyn määrää rehussa (1,06.sta 1,45 \%:iin). Rehut rakeistettiin (4 mm:n rae). Koerehujen $\mathrm{pH}$ mitattiin vesirehuseoksesta (50 g rehua ja $100 \mathrm{ml}$ vettä) 15 min kuluttua sekoittamisesta.

Porsaat saivat syödä koerehuja vapaasti automaatista vieroituksesta 25 päivän ajan. Porsaat punnittiin vieroituspäivänä sekä 11,18 ja 25 päivän kuluttua vieroituksesta. Rehunkulutus mitattiin punnitusväleittäin. Ulosteen kiinteys merkittiin ylös päivittäin käyttäen seuraavaa asteikkoa: $0=$ normaali, kiinteä uloste, 1 = löysä, puuromainen uloste, 2 = löysä, vellimäinen uloste ja 3 = vesiripuli. Jos ripuli oli vakavaa tai se jatkui useita päiviä ja porsaiden kunto alkoi heiketä, porsaille annettiin automaatista liuosta, joka sisälsi $1 \mathrm{rkl}$ glukoosia, 1 tl soodaa ja 1 tl suolaa per 11 vettä. Vakavimmat ripulitapaukset lääkittiin. Ripulin kestoa ja vakavuutta kuvaava ripuli-indeksi laskettiin päivittäisten ripulihavaintojen (vakavuusasteiden) summana.

Jokaisen koekäsittelyn 12 karsinasta kerättiin sontanäytteet 5, 10 ja 20 päivän kuluttua vieroituksesta. Näytteistä määritettiin kuiva-ainepitoisuus $\left(103{ }^{\circ} \mathrm{C}, 16 \mathrm{~h}\right)$, E. coli -bakteerien kokonaismäärä ja $\beta$-hemolyyttisten $E$. coli -pesäkkeiden osuus (\%). E. coli -määritykset tehtiin viljelemällä gramman sontanäyte sekä naudanveriagarilla (Becton-Dickinson Trypticase Soy Agar 4311047, johon on lisätty $5 \%$ defibrinoitua naudan verta) että EMB-agarilla (Oxoid Eosin Methylene Blue Agar CM69). E. coli -bakteerien määrä grammassa ulostetta määritettiin NMKL-nenetelmän (No. 44:1995) mukaan. Siinä sontanäytteitä laimennettiin 1/10 laimennoksin käyttäen Lab M puskuroitua peptonivettä (Lab 46). Eri laimennokset laitettiin sekä naudanveri- että VRB-agarille (OXOID Violet Red Bile Agar, CM107). E. coli -bakteerien kokonaismäärä laskettiin VRB-alustoilta, joissa oli 10-100 tyypillistä pesäkettä ja hemolyyttiset $E$. coli -pesäkkeet laskettiin veriagaralustoilta. Pesäkkeiden tyyppi vahvistettiin tarvittaessa viljelemällä niitä EMB-agarilla tai käyttäen API 20E systeemiä (Biomerieux).

Tulokset analysoitiin SAS-ohjelmistolla käyttäen mallia, jossa olivat mukana pahnueen satunnainen vaikutus, kantaja-aineen ja happoseosten kiinteät vaikutukset sekä näiden yhdysvaikutus. Sonnan vesi- ja E. coli -pitoisuudet analysoitiin toistomittauksina ja hemolyyttisten E. colipesäkkeiden osuuden (\%) analysoinnissa käytettiin muunnosta.

\section{Tulokset ja tulosten tarkastelu}

Happoseokset laskivat porsasrehun $\mathrm{pH}$ :ta vain vähän: hapottomien rehujen $\mathrm{pH}$ oli noin $5,5, \mathrm{~S}-$ happoseosta sisältäneiden rehujen noin 5,2 ja M-happoseosta sisältäneiden rehujen noin 5,1. Piimaakantaja-aine ei vaikuttanut rehun $\mathrm{pH}$-arvoon.

Porsaiden vieroituspaino oli piimaata sisältäneillä ruokinnoilla pienempi kuin kantajaaineettomilla ruokinnoilla $(10,0$ vs. $10,3 \mathrm{~kg}, \mathrm{P}<0,05)$, mikä todennäköisimmin johtui piimaaruokinnoille jaettujen porsaiden keskimäärin 0,9 päivää aikaisemmasta vieroituksesta (taulukko 1). Kokeen edetessä porsaiden painoero suureni kantaja-ainekäsittelyjenvälillä 1,3 kg:aan. Happolisäykset vaikuttivat merkitsevästi porsaiden painoon ainoastaan 18 päivän kuluttua vieroituksesta, jolloin S-happoseosta saaneet porsaat olivat $1,4 \mathrm{~kg}$ painavampia $(\mathrm{P}<0,05)$ kuin hapottomien ruokintojen porsaat. M-happoseosta saaneiden porsaiden paino ei eronnut hapottomien ruokintojen porsaiden painosta $(\mathrm{P}>0,05)$.

Porsaiden kasvussa oli ensimmäisten 11 koepäivän aikana lievä yhdysvaikutus happolisäyksen ja kantaja-aineen käytön välillä $(\mathrm{P}=0,12)$. Seuraavan koeviikon aikana $(11-18 \mathrm{pv}$ vieroituksesta) $\mathrm{S}$ happoseosta saaneet porsaat kasvoivat $85 \mathrm{~g} / \mathrm{pv}$ nopeammin kuin hapotonta rehua saaneet porsaat $(\mathrm{P}<$ $0,01)$, mutta $\mathrm{M}$-happoseosten ja hapottomien ruokintojen välillä ei ollut porsaiden kasvunopeudessa eroa $(\mathrm{P}>0,05)$. Viimeisen koeviikon (18-25 pv) kasvuissa ei ollut merkitseviä eroja koekäsittelyjen välillä. Koko kokeen aikainen kasvu oli piimaata sisältäneillä ruokinnoilla huonompi kuin kantajaaineettomilla ruokinnoilla (306 vs. $343 \mathrm{~g} / \mathrm{pv}, \mathrm{P}<0,05$ ). Kun vieroituspainojen väliset erot otettiin huomioon käyttämällä vieroituspainoa kovariaattina, kantaja-aineryhmien välinen ero pieneni (310 vs. $338 \mathrm{~g} / \mathrm{pv}, \mathrm{P}=0,06)$.

Porsaiden rehunkulutuksessa ei ollut ruokintaryhmien välillä merkitseviä eroja. Joissakin karsinoissa porsaat tuhlasivat rehua lattialle, mikä suurensi rehunkulutuksen vaihtelua karsinoiden välillä. Rehunkulutuksen mittauksen epätarkkuudesta huolimatta rehuhyötysuhde oli piimaata sisältäneillä ruokinnoilla huonompi kuin kantaja-aineettomilla ruokinnoilla (1,86 vs. $1,72 \mathrm{~kg} \mathrm{ka} / \mathrm{kasvu} \mathrm{kg}, \mathrm{P}<$ $0,01)$. 
Taulukko 1. Happoseosten ja kantaja-aineen vaikutukset porsaiden kasvuun, rehunkulutukseen, rehuhyötysuhteeseen ja ripulisuuteen $(\mathrm{N}=16$ karsinaa per käsittely).

\begin{tabular}{|c|c|c|c|c|c|c|c|c|c|c|}
\hline \multirow{2}{*}{$\begin{array}{l}\text { Happoseos } \\
\text { Kantaja-aine }\end{array}$} & \multirow{2}{*}{$\begin{array}{l}- \\
-\end{array}$} & \multirow{2}{*}{$\begin{array}{ll}- \\
+\end{array}$} & \multirow{2}{*}{$\begin{array}{l}\mathrm{S} \\
-\end{array}$} & \multirow{2}{*}{$\begin{array}{l}\mathrm{S} \\
+\end{array}$} & \multirow{2}{*}{$\begin{array}{l}M \\
-\end{array}$} & \multirow{2}{*}{$\begin{array}{c}\mathrm{M} \\
+\end{array}$} & \multirow[b]{2}{*}{ SEM } & \multicolumn{3}{|c|}{ Tilast. merk. $^{1}$} \\
\hline & & & & & & & & $\mathrm{H}$ & $\mathrm{K}$ & $\mathrm{H} \times \mathrm{K}$ \\
\hline Vieroitusikä, pv & 31,8 & 29,9 & 30,9 & 30,9 & 31,6 & 30,6 & & & & \\
\hline \multicolumn{11}{|l|}{ Paino, kg } \\
\hline Vieroitus & 10,3 & 10,0 & 10,4 & 10,0 & 10,4 & 10,0 & 0,2 & ns & $*$ & ns \\
\hline $11 \mathrm{pv}$ vieroituksesta & 12,2 & 11,5 & 12,1 & 12,0 & 12,5 & 11,7 & 0,4 & ns & $* *$ & ns \\
\hline 18 pv vieroituksesta & 14,7 & 14,0 & 15,5 & 14,9 & 15,4 & 14,1 & 0,4 & $*$ & $* *$ & ns \\
\hline 25 pv vieroituksesta & 18,4 & 17,4 & 19,0 & 18,1 & 19,4 & 17,5 & 0,6 & ns & $* *$ & ns \\
\hline \multicolumn{11}{|l|}{ Kasvu, g/pv } \\
\hline $0-11 \mathrm{pv}$ & 174 & 133 & 160 & 175 & 195 & 150 & 19 & ns & o & ns \\
\hline $11-18 \mathrm{pv}$ & 365 & 362 & 478 & 419 & 414 & 346 & 31 & $* *$ & $\mathrm{o}$ & ns \\
\hline $18-25 \mathrm{pv}$ & 508 & 464 & 505 & 466 & 544 & 503 & 39 & ns & ns & ns \\
\hline $0-25 \mathrm{pv}$ & 324 & 291 & 346 & 323 & 358 & 303 & 20 & ns & $*$ & ns \\
\hline $0-25$ pv (vier.paino kov.) & 321 & 296 & 344 & 327 & 349 & 308 & 19 & ns & o & ns \\
\hline \multicolumn{11}{|l|}{ Rehunkulutus, kg ka/pv } \\
\hline $0-25 \mathrm{pv}$ & 570 & 530 & 562 & 583 & 592 & 544 & 27 & ns & ns & $\mathrm{ns}$ \\
\hline \multicolumn{11}{|l|}{ Rehuhyötysuhde, $\mathrm{kg} \mathrm{ka} / \mathrm{kg}$} \\
\hline $0-25 \mathrm{pv}$ & 1,82 & 1,90 & 1,68 & 1,88 & 1,67 & 1,80 & 0,08 & ns & $*$ & ns \\
\hline Ripulipäivien lkm & 6,7 & 5,1 & 6,1 & 6,4 & 5,3 & 5,8 & 1,1 & ns & ns & ns \\
\hline \multicolumn{11}{|l|}{ Ripuli-indeksi } \\
\hline $0-11 \mathrm{pv}$ & 5,8 & 3,7 & 5,5 & 3,5 & 3,8 & 4,0 & 0,8 & ns & $*$ & ns \\
\hline $11-25 \mathrm{pv}$ & 3,6 & 3,5 & 3,7 & 4,1 & 2,8 & 3,6 & 1,1 & ns & ns & ns \\
\hline $0-25 \mathrm{pv}$ & 9,4 & 7,2 & 9,2 & 7,7 & 6,6 & 7,5 & 1,6 & ns & ns & ns \\
\hline \multicolumn{11}{|l|}{ Karsinoita, joissa } \\
\hline ei ripulihavaintoja & 2 & 3 & 1 & 2 & 4 & 0 & & & & \\
\hline pehmeää ulostetta & 5 & 3 & 3 & 3 & 4 & 4 & & & & \\
\hline kohtalaista ripulia & 4 & 4 & 2 & 5 & 4 & 5 & & & & \\
\hline vakavaa ripulia & 5 & 6 & 10 & 6 & 4 & 7 & & & & \\
\hline annettu ravintoliuosta & 3 & 1 & 7 & 3 & 1 & 4 & & & & \\
\hline lääkitty & 0 & 0 & 2 & 0 & 1 & 1 & & & & \\
\hline $\begin{array}{l}\text { Porsaita kuollut/lopetettu } \\
\text { ripulin vuoksi }\end{array}$ & 0 & 2 & 1 & 0 & 1 & 4 & & & & \\
\hline
\end{tabular}

Porsaiden kasvun hidastuminen ja rehuhyötysuhteen huononeminen piimaata sisältäneillä ruokinnoilla oli jossain määrin odottamatonta, sillä lihasikakokeessa piimaahan imeytetty muurahaishapposorbaattiseos paransi kasvua jo varsin pieniä happopitoisuuksia käytettäessä (Partanen ym. julkaisematon). Toisaalta kaoliinin käyttö ripuliporsaiden kuivumisen ehkäisemiseksi on huonontanut rehuhyötysuhdetta vieroitetuilla porsailla (Siljander-Rasi ym. 2002). Ei tiedetä, sitooko huokoinen piimaa suolistossa ravintoaineita estäen niiden imeytymisen, vai mistä kasvun ja/tai rehuhyötysuhteen huononeminen johtuvat. Happoseosten lisäystaso oli pienehkö aikaisemmissa tutkimuksissa käytettyihin lisäystasoihin verrattuna (Partanen ja Mroz 1999). Näillä happoseoksilla lisätty määrä ei todennäköisesti ollut riittävän suuri merkitsevän kasvun lisäyksen ja/tai rehuhyötysuhteen pienenemisen aikaan saamiseksi.

Kokeen 96 karsinasta $35 \%$ :ssa ei havaittu lainkaan ripulia tai ulosteiden löystymistä todettiin vain muutaman yksittäisenä päivänä kokeen aikana. Ripulia oli $65 \%$ :ssa karsinoista, ja $40 \%$ :ssa karsinoista ripuli oli vakavaa eli uloste oli vellimäistä tai vetistä ja ripulihavaintoja tehtiin useina peräkkäisinä päivinä kokeen aikana. Ripulipäivin lukumäärässä ei kuitenkaan ollut koekäsittelyjen välillä merkitseviä eroja. Ripulin vakavuutta kuvaava ripuli-indeksi oli ensimmäisten 11 koepäivän aikana piimaata sisältäneillä ruokinnoilla pienempi kuin kantaja-aineettomilla ruokinnoilla (3,7 vs. 5,1, $\mathrm{P}<0,05)$, mutta ei enää sen jälkeen. Koko kokeen aikaisessa ripuli-indeksissä ei ollut koeruokintojen välillä merkitseviä eroja. Kokeen aikana kuoli neljä porsasta ja neljä jouduttiin lopettamaan karsinoista, joissa oli vakavaa ripulia. Porsaiden kuolemat tapahtuivat ensimmäisten kahden koeviikon aikana, kun taas huonokuntoisia porsaita lopetettiin vähän myöhemmin, kolmannella koeviikolla. Kuolleista ja lopetetuista porsaista viisi lähetettiin tutkittavaksi EELA:aan ja useimmilla näistä löytyi suolistosta E. coli -bakteerien aiheuttama infektio. Yhdellä porsaalla todettiin akuutti mahahaava. 
Sonnan $E$. coli -määritykset tehtiin 5,10 ja 20 päivän kuluttua vieroituksesta, jolloin 57,65 ja $54 \%$ :ssa näytekarsinoista oli tehty ripulihavainto (taulukko 2). Näytteenottoajankohta vaikutti merkitsevästi sekä sonnan vesipitoisuuteen että $E$. coli -bakteerien kokonaismäärään ja hemolyyttisten E. coli -pesäkkeiden osuuteen $(\mathrm{P}<0,05)$. Sonnan vesipitoisuus pieneni lineaarisesti ajan myötä, mutta E. coli -bakteerien kokonaismäärä ja hemolyyttisten E. coli -pesäkkeiden osuus olivat suurimmillaan 10 pv vieroituksesta ja pienimmillään 20 pv vieroituksesta. Keskimmäinen näytteenottoajankohta sattui ripulihuipun kohdalle. Koekäsittelyjen välillä ei kuitenkaan havaittu merkitseviä eroja sonnan vesipitoisuudessa, E. coli -bakteerien kokonaismäärässä eikä hemolyyttisten $E$. coli -pesäkkeiden osuudessa.

Taulukko 2. Happoseosten ja kantaja-aineen vaikutukset sonnan vesipitoisuuteen ja E. coli -bakteerien kokonaismäärään $(\mathrm{N}=12$ karsinaa per käsittely).

\begin{tabular}{|c|c|c|c|c|c|c|c|c|}
\hline Happoseos & & - & - & $\mathrm{S}$ & $\mathrm{S}$ & M & M & \\
\hline Kantaja-aine & & - & + & - & + & - & + & SEM \\
\hline Vesipitoisuus, $\%$ & & 74,0 & 73,6 & 75,0 & 74,0 & 74,1 & 73,5 & 0,7 \\
\hline 5 pv vieroituksesta & 74,8 & 75,2 & 74,1 & 76,0 & 75,1 & 74,9 & 76,0 & 1,0 \\
\hline $10 \mathrm{pv}$ vieroituksesta & 73,8 & 73,5 & 73,2 & 74,8 & 74,5 & 73,7 & 73,1 & 1,0 \\
\hline 20 pv vieroituksesta & 73,5 & 73,2 & 73,6 & 74,2 & 72,4 & 73,6 & 74,1 & 1,0 \\
\hline SEM & 0,4 & & & & & & & \\
\hline E. coli, $\log _{10}$ pesäkettä/g & & 6,7 & 6,4 & 7,0 & 6,7 & 6,6 & 6,6 & 0,2 \\
\hline 5 pv vieroituksesta & 7,0 & 6,9 & 6,7 & 7,4 & 7,1 & 6,7 & 7,3 & 0,4 \\
\hline $10 \mathrm{pv}$ vieroituksesta & 7,2 & 7,2 & 7,0 & 7,8 & 7,4 & 7,2 & 6,7 & 0,4 \\
\hline $20 \mathrm{pv}$ vieroituksesta & 5,7 & 6,1 & 5,4 & 5,6 & 5,4 & 5,8 & 5,7 & 0,4 \\
\hline SEM & 0,2 & & & & & & & \\
\hline Hemolyyttisiä pesäkkeitä, \% & & 45 & 35 & 32 & 42 & 31 & 37 & 6 \\
\hline 5 pv vieroituksesta & 38 & 37 & 43 & 21 & 58 & 35 & 33 & 11 \\
\hline $10 \mathrm{pv}$ vieroituksesta & 50 & 49 & 46 & 48 & 53 & 45 & 57 & 11 \\
\hline 20 pv vieroituksesta & 24 & 50 & 15 & 27 & 14 & 14 & 21 & 11 \\
\hline SEM & 6 & & & & & & & \\
\hline
\end{tabular}

\section{Johtopäätökset}

Tulosten perusteella 5,1 g piimaakantaja-ainetta kg:ssa rehua huononsi sekä porsaiden kasvua että rehuhyötysuhdetta. Kantaja-aineen käyttö kuitenkin pienensi vieroitusripulin vakavuutta ja kestoa kuvaavaa ripuli-indeksiä ensimmäisten 11 päivän aikana vieroituksesta, mutta ei sen jälkeen. Porsasrehuun lisätyillä useiden happojen ja suolojen seoksilla ei ollut $4,9 \mathrm{~g} / \mathrm{kg}$ lisäystasolla vaikutusta porsaiden kasvuun, rehuhyötysuhteeseen eikä ripulisuuteen. Kantaja-aine ja happoseokset eivät vaikuttaneet sonnan E. coli -bakteerien määrään, joka oli suurimmillaan 10 pv vieroituksesta.

\section{Kirjallisuus}

Cochran, W.G., Cox, G.M. 1957. Experimental designs. 2.th ed. New York: Wiley \& Sons. 611 s.

Korunic, Z. 1998. Diatomaceous earths, a group of natural insecticides. J. Stored Prod. Res. 34: 87-97.

MTT 2004. Rehutaulukot ja ruokintasuositukset 2004. Helsinki: Maa- ja elintarviketalouden tutkimuskeskus. MTT:n selvityksiä $86.82 \mathrm{~s}$. http://www.mtt.fi/mtts/pdf/mtts86.pdf

Partanen, K., Siljader Rasi, H., Alaviuhkola, T., Suomi, K., Fossi, M. 2002. Performance of growingfinishing pigs fed medium- or high-fibre diets supplemented with avilamycin, formic acid or formic acid-sorbate blend. Livest. Prod Sci 73: 139-152.

Partanen, K.H., Mroz, Z. 1999. Organic acids for performance enhancement in pig diets. Nutr.Res. Rev. 12, 1: $117-145$.

Siljander-Rasi, H., Laurinen, P., Huhtinen, M., Pelkonen, S., Pentikäinen, J. 2002. Porsaiden vieroitusripulin tukihoito. Suomen Eläinlääkärilehti 108: 344-345.

Veldman, A., van der Aar, P.J. 1997. Effects of dietary inclusion of a natural clinoptilolite (ManneliteTM) on piglet performance. Agribiol. Res. 50: 289-294. 